\title{
Gender difference and sex hormone production in rodent renal ischemia reperfusion injury and repair
}

\author{
René Robert ${ }^{1,5^{*}}$, Daniel Aiham Ghazalii, ${ }^{2,5}$, Frédéric Favreau ${ }^{3,5}$, Gérard Mauco ${ }^{3,5}$, Thierry Hauet ${ }^{3,5}$ and \\ Jean-Michel Goujon ${ }^{4,5}$
}

\begin{abstract}
Background: Several lines of evidence suggest a protective effect of female sex hormones in several organs subjected to ischemia-reperfusion injury. The aim of the study was to investigate sex hormone production in male rats after a renal ischemia-reperfusion sequence and analyze the influence of gender differences on tissue remodelling during the recovery process.

Method: Age-matched sexually mature male and female rats were subjected to $60 \mathrm{~min}$ of renal unilateral ischemia by pedicle clamping with contralateral nephrectomy and followed for 1 or 5 days after reperfusion. Plasma creatinine, systemic testosterone, progesterone and estradiol levels were determined. Tubular injury, cell proliferation and inflammation, were evaluated as well as proliferating cell nuclear antigen, vimentin and translocator protein (TSPO) expressions by immunohistochemistry.

Results: After 1 and 5 days of reperfusion, plasma creatinine was significantly higher in males than in females, supporting the high mortality in this group. After reperfusion, plasma testosterone levels decreased whereas estradiol significantly increased in male rats. Alterations of renal function, associated with tubular injury and inflammation persisted during the 5 days post-ischemia-reperfusion, and a significant improvement was observed in females at 5 days of reperfusion. Proliferating cell nuclear antigen and vimentin expression were upregulated in kidneys from males and attenuated in females, in parallel to injury development. TSPO expression was transiently increased in proximal tubules in male rats.

Conclusions: After ischemia, renal function recovery and tissue injury is gender-dependent. These differences are associated with a modulation of sex hormone production and a modification of tissue remodeling and proliferative cell processes.
\end{abstract}

\section{Background}

Several lines of evidence suggest that both humoral and cell-mediated immunity are more active in females than in males [1]. Sex steroid hormones could play a pivotal role $[2,3]$ in this process, and act as regulators of inflammatory processes. Indeed, numerous inflammatory cell functions, such as neutrophil chemoattractant generation, phagocytic responses of neutrophils [4], and nitric oxide production by alveolar macrophages [5] show gender differences.

\footnotetext{
* Correspondence: r.robert@chu-poitiers.fr

${ }^{1} \mathrm{CHU}$ Poitiers, Service de Réanimation Médicale Poitiers, F-86000, France Full list of author information is available at the end of the article
}

Ischemia-reperfusion injury (IRI) is known to exacerbate a pro-inflammatory milieu. The influence of gender on IRI has been mainly studied in cardiac ischemia and it is now established that female steroid hormones play a protective role [6-8]. In liver, it was reported that female mice were protected from liver ischemia-reperfusion compared to males, linked to an estrogen-dependent mechanism $[9,10]$. In a renal ischemia-reperfusion model, the mortality rate was significantly greater in male rodents $[11,12]$. Orchidectomy significantly improved male survival [11] and testosterone may increase kidney ischemic injury in mice [13]. These results suggest a protective effect of female hormones,
C Biomed Central

C 2011 Robert et al; licensee BioMed Central Ltd. This is an Open Access article distributed under the terms of the Creative Commons Attribution License (http://creativecommons.org/licenses/by/2.0), which permits unrestricted use, distribution, and reproduction in any medium, provided the original work is properly cited. 
and a detrimental effect of male hormones. However, although sex hormones could play an important role, the direct gender influence has not been fully demonstrated in renal ischemia-reperfusion models and the mechanisms involved remain to be elucidated.

We have previously demonstrated, in a rodent kidney ischemia-reperfusion model, that extensive renal tissue injury such as proximal tubule necrosis and outer medulla congestion occurred during the reperfusion phase following $60 \mathrm{~min}$ of ischemia [14]. In these conditions, tissue remodelling is determined by the severity of ischemia as we have previously shown in a pig model of renal ischemia reperfusion [15]. Tissular regeneration could be a pivotal key of organ outcome, limiting or counteracting injury development. Different markers of tissue remodelling or regeneration have been used in renal tissue such as vimentin, alpha-smooth muscle actin $(\alpha-$ SMA $)$, proliferating cell nuclear antigen (PCNA) or translocator protein (TSPO) expressions. TSPO, formerly known as the peripheral-type benzodiazepine receptor [16], is a widely distributed transmembrane protein that is localized mainly in the outer mitochondrial membrane. Many functions are associated directly or indirectly with TSPO, including the regulation of cholesterol transport and steroid hormones synthesis, porphyrin transport and heme synthesis, apoptosis, cell proliferation, anion transport, regulation of mitochondrial functions and immunomodulation $[16,17]$. TSPO expression has been shown to be modulated by renal ischemia-reperfusion injury, in particular during the repair process $[18,19]$. Under these conditions, IRI could affect TSPO expression and sex hormone production respectively, modulating cellular response.

The aim of this study was to investigate sex hormone production in male rats subjected to renal ischemiareperfusion, and analyze the influence of gender differences on tissue remodelling markers, particularly on cell proliferation processes and TSPO expression in the early phase of reperfusion.

\section{Material and methods} Ischemia-reperfusion procedure

Age-matched (4 to 5 month-old) male and female Sprague-Dawley rats weighting 220-380 g were studied (Depré, France). All animals were sexually mature. The surgical and experimental protocols were performed in accordance with the French Ministry of Agriculture for the use and care of laboratory animals. The protocol was approved by the local Ethical Committee for animal study and referenced with the number 0206.

\section{Experimental Design}

Eight rats ( 4 males and 4 females) were considered as controls and received only anesthesia and sham surgery.
Ischemia-reperfusion experiments were performed in 40 rats, including 21 male and 19 female rats. On the day of experiment, animals were anesthetized with an intramuscular injection of a mix of medetomidine chlorhydrate $0.4 \mathrm{mg} / \mathrm{kg}$ (Pfizer, Orsay, France) and ketamine chlorhydrate $25 \mathrm{mg} / \mathrm{kg}$ (Pfizer, Orsay, France). In all rats, after a middle laparotomy incision, the right kidney was removed, mimicking the clinical conditions of nephron mass reduction. Ischemia was induced in the contralateral kidney by clamping the renal artery. After 60 minutes, the non traumatic clamp was removed inducing renal reperfusion and the abdomen wall was closed. Blood samples were collected at different time intervals for plasma creatinine and hormone levels determination. Plasma creatinine concentrations were determined using a Hitachi 917 automatic analyzer (Roche Diagnostic, Meylan, France). At the time of sacrifice, rats were anesthetized using the protocol described above and left kidney was removed. Three end-points were studied for male and female rats: D0 (kidney removed immediately after the 60-min ischemia without reperfusion, $\mathrm{n}=6$ males and 5 females), D1 (kidney removed after the 60-min ischemia and 24 hours of reperfusion, $\mathrm{n}=7$ males and 6 females) and D5 (kidney removed after the 60-min ischemia and 5 days of reperfusion, $\mathrm{n}=8$ males and 8 females). Two female rats died immediately after anesthesia, before undergoing ischemia-reperfusion experiment, and were not considered in data analysis.

\section{Histochemical and immunohistochemical studies}

Samples were fixed in Dubosq-brazil, 10\% formalin in 0.01 $\mathrm{mM}$ phosphate buffer ( $\mathrm{pH} 7.4$ ), and embedded in paraffin. Then, periodic acid-Schiff staining was applied for histochemical analysis. A pathologist performed analyses in a blinded fashion using standard histopathological method. Two basic histological patterns typical of proximal tubular injury: loss of brush border and cell detachment, were graded according to a published semi-quantitative score using a 5-point scale as follows: 0 , no abnormalities, 1 , mild lesions affecting less than $25 \%$ of kidney section; 2 lesions affecting $25 \%$ to $50 \%$ of kidney section; 3 lesions affecting $50 \%$ to $75 \%$ of kidney section; and 4 lesions affecting more than $75 \%$ of kidney section [20].

We assessed cell proliferation and dedifferentiation to evaluate the time course of proximal tubule cell regeneration after IRI. We used specific antibodies against PCNA (1:100, Neomarkers Data Sheet, Lab Vision, UK), and vimentin (1/100, Dakopatts, Denmark) as markers respectively of cell proliferation and cell dedifferentiation. We established the percentage of vimentin-positive proximal tubule cells and the proliferation index (PI) as the percentage of PCNA-positive nuclei, in ten highpower fields $(x 400)$. Patterns of TSPO expression in 
kidney, was analysed using a rabbit polyclonal antibody anti-mouse TSPO (1/100, a gift from Vassilios Papadopoulos Department of Biochemistry and Molecular Biology, Georgetown University, Washington DC, USA) directed against amino acid sequences conserved across species [21]. TSPO immunostaining was graded using an arbitrary scale: 0: No staining; 1: Faint staining; 2: Moderate staining; and 3: Strong staining. Infiltrated neutrophils and $\mathrm{T}$ lymphocytes, indicating innate and adaptative immunity, were detected respectively using anti-Ly6G (GR-1, 1/1000, eBiosciences, San Diego, USA) and anti-CD3 (1/200, Dakopatts) antibodies. The number of Ly6G and CD3 positive labeled cells per surface areas $\left(10^{4} \mu \mathrm{m}^{2}\right)$ were counted on ten different kidney tissue sections.

\section{Male sex hormone quantification}

Testosterone, progesterone and estradiol levels were evaluated in systemic blood by double antibody radioimmunoassay (DA RIA; Diagnostic Systems Laboratories, Inc (DSL), Texas, USA).

\section{Statistical Analysis}

Data were expressed as mean \pm standard error of the mean (SEM). Continuous values were compared using Student's t test. The Mann-Whitney-Wilcoxon signedranks test was used for non Gaussian distribution. Statistical significance was defined as $\mathrm{p}<0.05$.

\section{Results}

Effect of ischemia-reperfusion on renal functional parameters and kidney outcome

Plasma creatinine levels (table 1) were increased with similar degree in males and females at the end of the ischemic period (D0) $(96.1 \pm 5.6$ vs. $118.0 \pm 6.9)$. After 1 and 5 days of reperfusion, plasma creatinine was significantly higher in males than in females (D1, 345.0 \pm 6.6 vs. $200.5 \pm 6.6 ; \mathrm{D} 5,511.7 \pm 6.4$ vs. $253.0 \pm 6.6 \mu \mathrm{mol} / \mathrm{L}$; p $<0.05$ and $<0.01$ respectively). Plasma creatinine concentrations in each group before ischemia-reperfusion sequences did not show statistical difference (data not shown). These results were supported by survival analysis demonstrating a poor survival rate in males compared to females (at day 5, 5 out of 8 males died whereas only 3 out of 8 females died).

\section{Effect of ischemia-reperfusion on male sex hormone production}

As shown in table 2, hormone plasma levels (estradiol, progesterone and testosterone) did not show significant differences after $60 \mathrm{~min}$ of ischemia compared to basal values. After $24 \mathrm{~h}$ of reperfusion, estradiol was drastically increased compared to basal values $(64.0 \pm 9.0$ vs. $8.3 \pm 0.7 \mathrm{pmol} / \mathrm{L}, \mathrm{p}<0.05)$ whereas testosterone levels decreased $(0.7 \pm 0.6$ vs. $2.4 \pm 0.8 \mathrm{nmol} / \mathrm{L}, \mathrm{p}<0.05)$. Progesterone levels remained unchanged after 1 day of reperfusion. After 5 days of reperfusion, estradiol increased further up to $336.0 \pm 16.8 \mathrm{pmol} / \mathrm{L}$, whereas progesterone levels fell to $4.1 \pm 1.8 \mathrm{nmol} / \mathrm{L}$.

\section{Influence of gender difference on tissue remodeling and cellular proliferation after renal ischemia-reperfusion injury}

Warm ischemia with or without 24 h of reperfusion, regardless of gender, induced an extensive tubular injury characterized by tubular necrosis linked to a loss of the apical brush border and intraluminal desquamation. Interestingly, renal lesion levels in males remain high whereas significant improvement was observed in female rats at day 1 or day 5 respectively for cell detachment or loss of brush border determinations (table 3, figure 1). The immunohistochemical studies showed an interstitial infiltration of inflammatory cells after ischemia and during the early reperfusion phase. Infiltrating neutrophils mainly presented at day 1 , decreased at day 5 with a drastic increase of CD3 positive lymphocytes (figure 2). These cellular infiltrations at day 5 were significantly attenuated in kidney from female rats compared to males. These results were supported by the PCNA and vimentin immunostaining, which were dramatically

Table 1 Male and female rat plasma creatinine concentrations (mean \pm SEM) in control, after ischemia (DO), and ischemia followed by 1 (D1) or 5 days (D5) of reperfusion

\begin{tabular}{ccc}
\hline Experimental conditions & Gender & Plasma creatinine concentrations $(\boldsymbol{\mu m o l} / \mathbf{L})$ \\
\hline Control & Male $(n=4)$ & $40.3 \pm 2.4$ \\
& Female $(n=4)$ & $31.6 \pm 1.7$ \\
D0 & Male $(n=6)$ & $96.1 \pm 5.6$ \\
& Female $(n=5)$ & $118.0 \pm 6.9$ \\
D1 & Male $(n=7)$ & $345.0 \pm 6.6 *$ \\
& Female $(n=6)$ & $200.5 \pm 6.6$ \\
D5* & Male $(n=3)$ & $511.7 \pm 6.4^{* *}$ \\
& Female $(n=5)$ & $253.0 \pm 6.6$ \\
\hline
\end{tabular}

*Five male and three female rats died before day $5 .{ }^{*} \mathrm{p}<0.05 ;{ }^{* *} \mathrm{p}<0.01$ male vs. female 
Table 2 Sex hormone concentrations in blood from male rats (mean \pm SEM) in control, after ischemia (D0) and ischemia followed by 1 (D1) or 5 days (D5) of reperfusion

\begin{tabular}{cccc}
\hline & Estradiol (pmol/L) & Progesterone (nmol/L) & Testosterone (nmol/L) \\
\hline Control $(n=4)$ & $8,3 \pm 0,7$ & $9,2 \pm 2.8$ & $2,4 \pm 0,8$ \\
\hline D0 $(n=6)$ & $7,7 \pm 0,8$ & $10,2 \pm 3.1$ & $1,7 \pm 1.2$ \\
\hline D1 $(n=7)$ & $64.0 \pm 9.0^{\mathrm{a}}$ & $8,9 \pm 2.9$ & $0,7 \pm 0.6^{\mathrm{a}}$ \\
\hline D5 $(n=3)$ & $336.0 \pm 16.8^{\mathrm{a}}$ & $4,1 \pm 1.8$ & $1,8 \pm 1.7$ \\
\hline
\end{tabular}

${ }^{a} \mathrm{p}<0.05$ compared to D0

increased in male rat kidneys, in comparison to female (table 4, figure 3 and figure 4), indicating a gender effect on regeneration processes. At Day 1, male rat kidneys exhibited a faint transient TSPO staining in proximal tubular epithelial cells (figure 5). In contrast, distal portions of nephrons, including distal tubules and collecting ducts, exhibited a strong cytoplasmic expression and no gender difference was detected (figure 5).

\section{Discussion}

In uninephrectomized mature rats, renal ischemia-reperfusion resulted in a severe acute renal failure, which affected more predominantly male than female animals as previously reported [11-13,22,23]. In our study, we showed a higher mortality rate for males in comparison to females following 60-min of renal ischemia with contralateral nephrectomy, associated with further deterioration of kidney function. The modulation of systemic male sex hormone levels by renal ischemiareperfusion could explain male sensitivity to renal injury. Experiments with orchidectomy or ovariectomy as well as with various hormone treatments in male and female animals helped demonstrate the crucial role of sex hormones. Indeed, administration of estradiol in myocardial ischemia-reperfusion induced a rapid recovery of hemodynamic parameters $[6,8]$. Moreover, exogenous estradiol attenuates the hepatocellular injury induced by ischemia reperfusion in a reduced-size liver mouse model [9]. These results support a protective effect of female sex hormone in several organs subjected to IRI. In male rats, renal IRI was improved by orchidectomy and by estradiol administration, suggesting that either lowering androgen concentrations, or increasing the estradiol-androgen ratio, may have a protective role $[11,13]$. In contrast, in females, ovariectomy and or testosterone administration did not have any impact on renal function after IRI $[11,13]$. In addition, it was reported that male sex steroids cause immune suppression, while female sex hormones maintain immune response following trauma-hemorrhage [24]. In the present study, we showed a decrease in testosterone plasma levels after 1 day of reperfusion and a concomitant large increase in estradiol plasma levels. In accordance with our findings, this modulation has also been reported in male rats during experimental septic shock [25] and trauma-hemorrhage shock [26]. The activation of extratestis aromatase transforming testosterone into estradiol has been found to be involved in experimental septic and hemorrhagic animal models and potentially due to upregulation of aromatase expression likely induced by acute increase in adrenal cortisol production [27]. However, the influence of decreased plasma testosterone and increased estradiol levels on tissue remodelling remains to be elucidated. Following the hypothesis of a detrimental effect of testosterone, and a protective effect of estradiol, we can speculate that our results may be due to compensatory regulatory effects. In addition, the trend towards a decrease in progesterone levels could explain, at least in part, the sensitivity of males to renal IRI.

After ischemia, kidneys from uninephrectomized male and female rats develop, at early reperfusion time points, a similar pattern of histopathological damages, according to previous reports [14]. Importantly, we showed that prolonged reperfusion (5 days) induced more severe tubular damage in kidneys from male compared to

Table 3 Semi-quantitative measurement of renal tubular injury, and determination of T lymphocytes (CD3+) and neutrophils (Ly6G+) infiltration per surface areas $\left(10^{4} \mu \mathrm{m}^{2}\right)$ in kidneys from male and female rats in control, after ischemia (D0) and ischemia followed by 1 (D1) or 5 days (D5) of reperfusion (mean \pm SEM)

\begin{tabular}{cccccccccc}
\hline $\begin{array}{c}\text { Experimental conditions } \\
\text { Gender }\end{array}$ & Male & Female & Male & Female & Male & Female & Male & Female \\
\hline LBB & $1.0 \pm 0.0$ & $1.0 \pm 0.0$ & $2.5 \pm 0.2$ & $2.5 \pm 0.2$ & $3.9 \pm 0.1$ & $3.5 \pm 0.2$ & $3.0 \pm 0.3^{*}$ & $2.0 \pm 0.2$ \\
CD & $1.0 \pm 0.0$ & $1.0 \pm 0.0$ & $1.5 \pm 0.2$ & $1.5 \pm 0.2$ & $3.1 \pm 0.1^{*}$ & $2.2 \pm 0.2$ & $2.0 \pm 0.3$ & $1.3 \pm 0.2$ \\
T CD3+ cells & $2.7 \pm 0.3$ & $2.6 \pm 0.2$ & $3.4 \pm 0.3^{*}$ & $1.6 \pm 0.1$ & $1.6 \pm 0.2$ & $1.3 \pm 0.3$ & $13.3 \pm 0.8^{*}$ & $9.8 \pm 0.6$ \\
Ly6G+ cells & 0 & 0 & $1.2 \pm 0.4$ & $0.6 \pm 0.3$ & $9.5 \pm 0.5^{*}$ & $3.8 \pm 0.6$ & $2.1 \pm 0.3^{*}$ & $0.8 \pm 0.3$ \\
\hline
\end{tabular}

LBB: Loss of Brush Border; CD: Cell Detachment, ${ }^{*} \mathrm{p}<0.05$ vs. Female. 


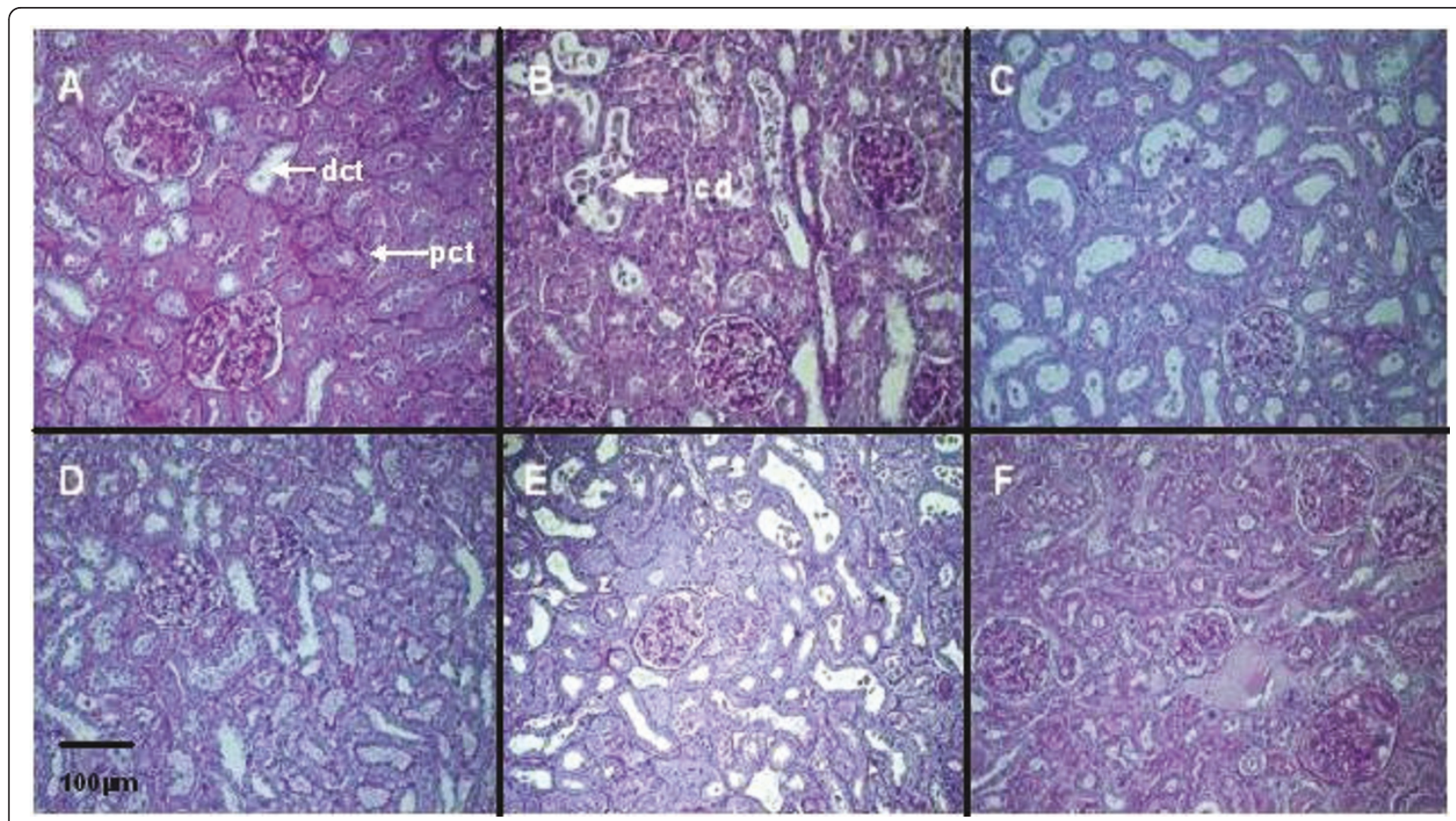

Figure 1 Renal histological evaluation by light microscopy (Periodic Acid-Schiff, $\times \mathbf{4 0 0}$ ). Proximal tubular epithelial cell injury in kidneys from male $(A, B, C)$ and female rats $(D, E, F)$ : basal conditions $(A$ and $D)$, after ischemia followed by $1(B$ and $E)$ or 5 days of reperfusion (C and F). pct: proximal convoluted tubule; dct: distal convoluted tubule; cd: cell detachment.

female rats. In the past, only few studies, including histological data, have been performed both in male and female rodents [11-13,22,23]. Hu et al. showed that ischemia time necessary to obtain IRI in mice was 35 to $45 \mathrm{~min}$ in male and $75 \mathrm{~min}$ in female, suggesting increased sensitivity of males to IRI [12]. According to these results, in a limited number of mice, Park et al. showed higher severe proximal tubular damage in males in comparison to females after $30 \mathrm{~min}$ of ischemia combined with $24 \mathrm{~h}$ of reperfusion [13]. In contrast, using a similar model, Muller et al. failed to show any histological differences between sexes after reperfusion [11]. This discrepancy with our results is likely due to the different ischemia-reperfusion times.

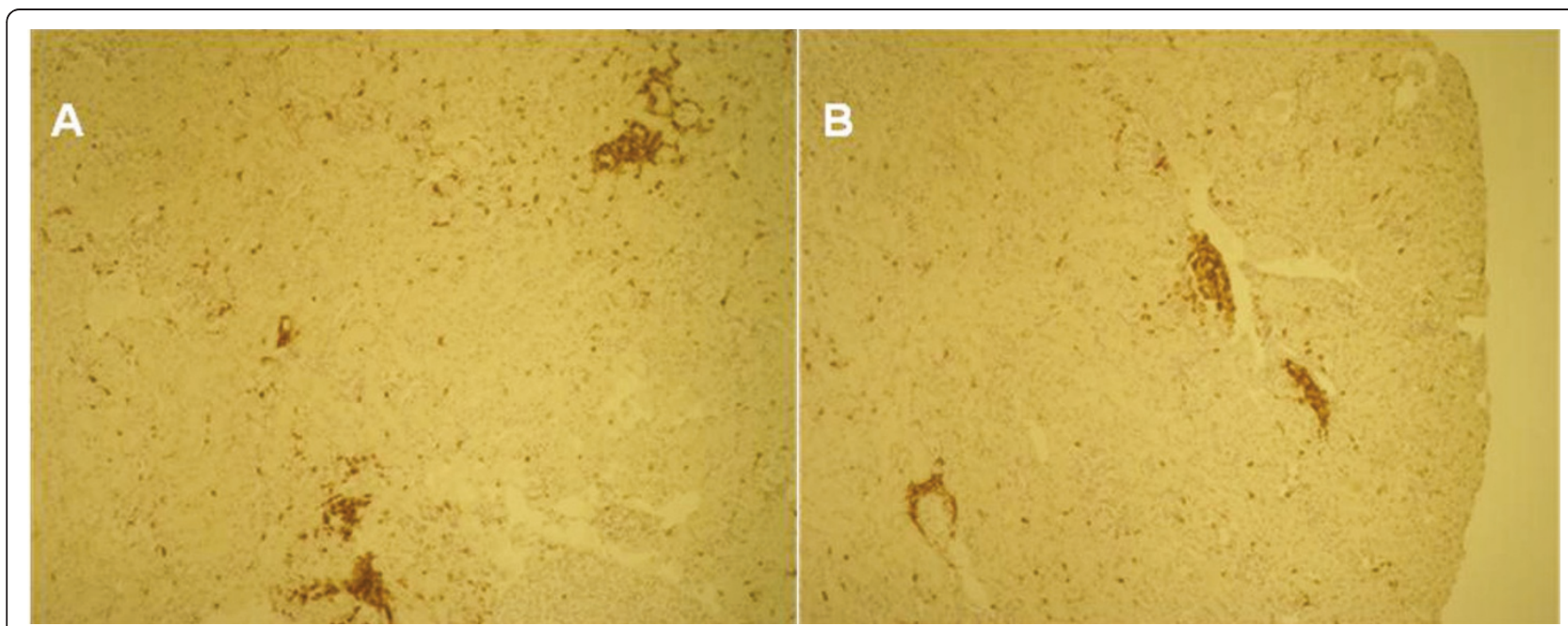

Figure 2 Interstitial inflammatory changes: In all times studied, CD3+ T lymphocytes are the major inflammatory cell population. A; Kidney from Rat Male at Day 5. B; Kidney from Female Rat At Day 5. Magnification $\times 100$. 
Table 4 Semi-quantitative evaluation (mean \pm SEM) of renal PCNA and vimentin expressions in male and female rats in control, after ischemia (DO) and ischemia followed by 1 (D1) or 5 days (D5) of reperfusion

\begin{tabular}{lcc}
\hline & Male & Female \\
\hline PCNA index (\%) & & \\
Control & $1.5 \pm 1.2$ & $0.8 \pm 0.9$ \\
D0 & $5.4 \pm 0.7$ & $5.1 \pm 0.8$ \\
D1 & $80.0 \pm 3.1^{*}$ & $10.6 \pm 1.1$ \\
D5 & $41.4 \pm 2.1^{*}$ & $13.3 \pm 1.1$ \\
\hline
\end{tabular}

Vimentin (\%)

$\begin{array}{lcc}\text { Control } & 0 & 0 \\ \text { D0 } & 0.3 \pm 0.7 & 0.2 \pm 0.6 \\ \text { D1 } & 14.2 \pm 1.7^{*} & 5.0 \pm 1.3 \\ \text { D5 } & 9.1 \pm 0.8^{*} & 2.9 \pm 0.6\end{array}$

${ }^{*} p<0.0001$ vs. Female.

\begin{tabular}{lcccc}
\hline TSPO & \multicolumn{2}{c}{ Proximal tubule } & \multicolumn{2}{c}{ Distal tubule } \\
\hline \multirow{2}{*}{ Control } & Male & Female & Male & Female \\
D0 & 0 & 0 & +++ & +++ \\
D1 & 0 & 0 & +++ & +++ \\
D5 & + & 0 & +++ & +++ \\
& 0 & 0 & +++ & +++
\end{tabular}

We used an arbitrary grading scale to assess TSPO expression: 0 : No staining; +: Faint staining; ++: Moderate staining; and +++: Strong staining. This staining level is representative of ten high-power fields in each experimental condition.
Inflammation is a major component of renal IRI. In our study, kidney from female exhibited a less degree of inflammation as shown by CD3 positive cells and neutrophils recruitment. Previous studies have already demonstrated the role of $\mathrm{T}$ lymphocytes as modulators of renal IRI and neutrophils as critical mediators of renal parenchymal injury [15] suggesting in our condition a protection against cellular infiltration related to gender.

Renal tubular epithelial cell dedifferentiation is thought to be a prerequisite for regenerative proliferation after IRI [28]. During the recovery process, surviving kidney cells dedifferentiated to mesenchymal phenotype and then proliferated and migrated to replace lost cells, commonly accepted as an epithelial mesenchymal transition process [29]. Under these conditions, new expression of mesenchymal markers like vimentin occurred in deteriorating and atrophic tubules. Vimentin is an intermediate filament protein expressed only in the mesenchymal cells and has been used as a marker for epithelial mesenchymal transition [30]. In a rat renal vascular occlusion model, Witzgall et al. previously reported that vimentin was detected 1 day post-clamping and prominently expressed 5 days after reperfusion [28]. Concomitantly with vimentin expression, authors

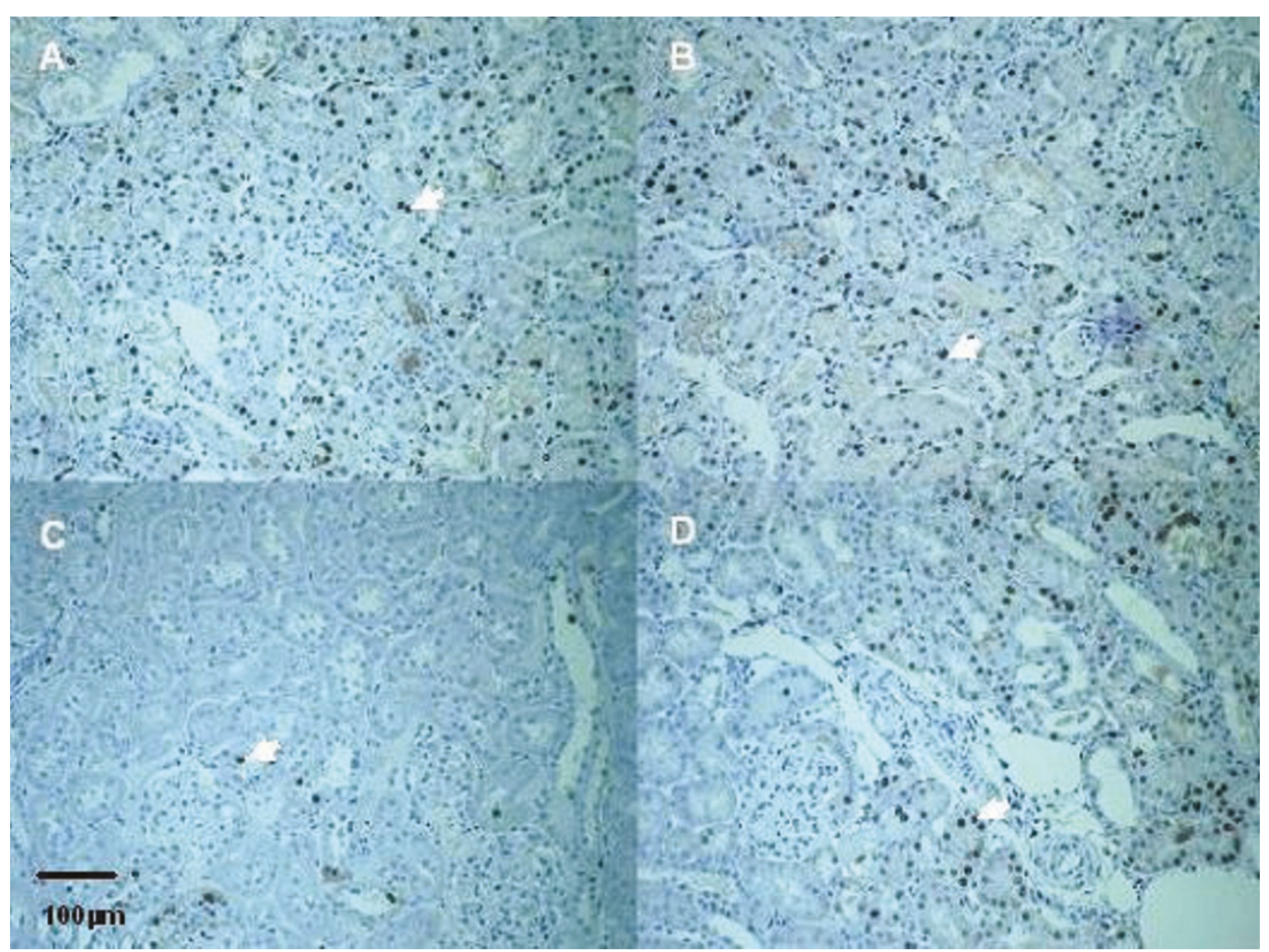

Figure 3 Representative proximal tubular PCNA staining (arrow). Kidneys from male (A, B) and female rats (C, D); after ischemia followed by 1 (A, C) or 5 days of reperfusion (B, D) (Magnification $\times 200)$. 


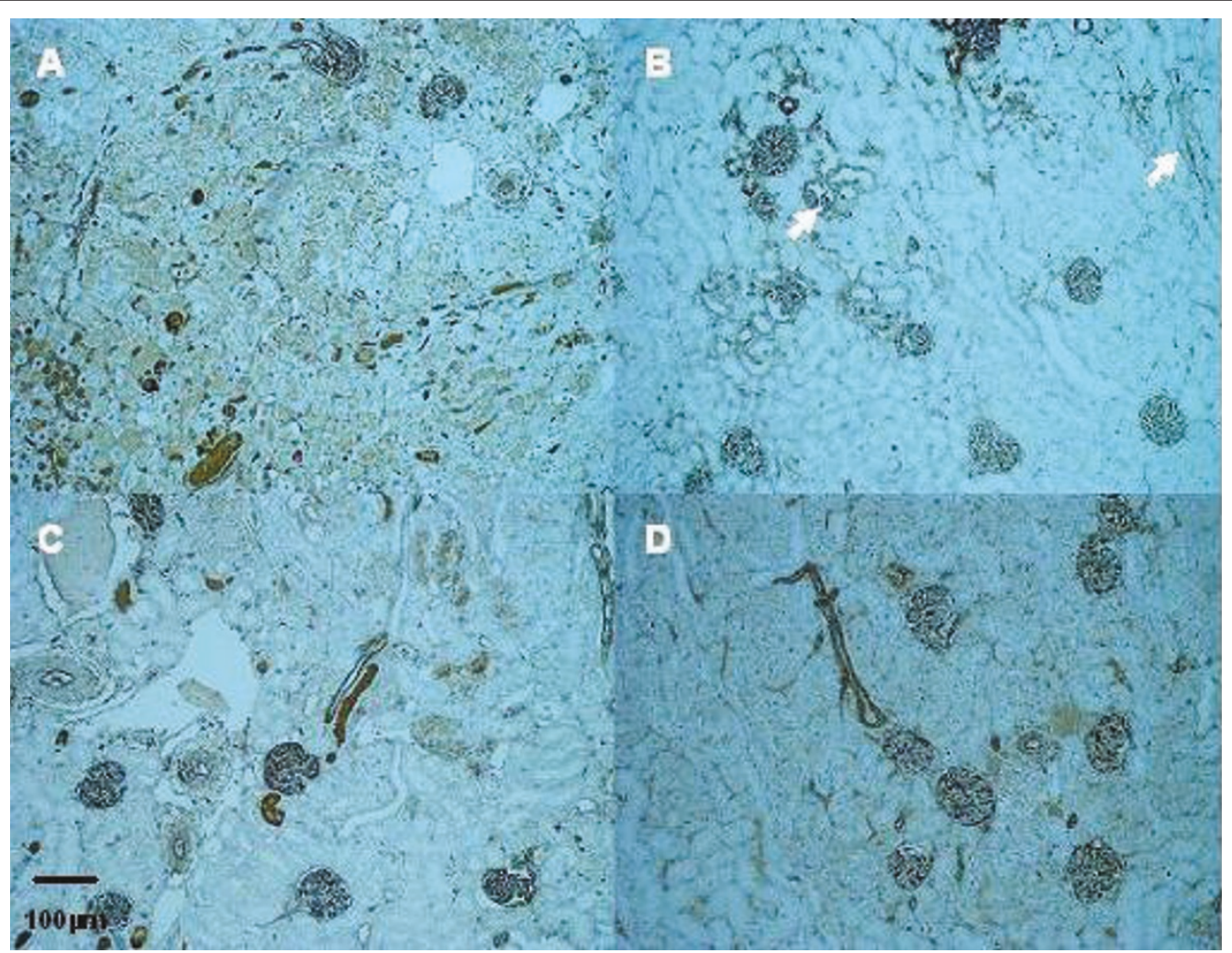

Figure 4 Representative vimentin expression (arrow). Kidneys from male (A, B) and female rats (C, D); after ischemia followed by 1 ( $A$, C) or 5 days of reperfusion $(B, D)$ (Magnification $\times 200)$.

described a maximal expression of PCNA 2 days postischemia in the proximal tubule [28]. PCNA is a marker for the G1-S transition phase cell cycle and hence mitogenesis. In our study, PCNA and vimentin expression analysis indicated a nephrogenic repair process more pronounced in male rats than in the female rats, related to a more severe injury after reperfusion. These results support a predominant tissue remodelling in male rats related to an extensive renal injury. However, at Day 5, in the female group a decrease in PCNA index and vimentin expression was associated with attenuation of tubular disorders, whereas in males these markers remained elevated in relation to a persistence of major tubular disorders. This underscores gender differences in renal tubular alterations and tissue remodelling after IRI.

There is increasing evidence that mitochondria play a central role in IRI mechanisms [31,32]. Our results supported a previous study in a porcine renal ischemiareperfusion model, which showed that mitochondrial TSPO protein expression was increased $24 \mathrm{~h}$ after reperfusion, particularly in the proximal tubule, which does not express this protein constitutively [33]. In addition, we have recently suggested that TSPO integrity is required for renal proximal tubular cell survival [18] and previous studies demonstrated its implication in cell cycle regulation $[16,34]$. In the present study, TSPO expression was more pronounced in proximal tubules of male rats after $24 \mathrm{~h}$ of reperfusion, in association with the severity of tubular injury and PCNA staining. The renal distal tubular epithelial cells which express constitutively TSPO, are well adapted to the hypoxic environment of the renal medulla and appear to be more able to withstand hypoxic stress than the epithelium of the proximal tubule $[35,36]$. The transient expression of TSPO in proximal tubular cells paralleled with PCNA staining results at $\mathrm{D} 1$, suggested a transient putative role of TSPO in the mitochondria biogenesis and cell functions at the early time of reperfusion. However, TSPO modulation was not clearly correlated with steroid synthesis. Collectively, these data support the different roles of TSPO depending on its location. In steroid-producing tissues (adrenal glands and gonads), TSPO has been implicated in the regulation of cholesterol transport into the mitochondria, where it is metabolized by CYP11A1 to pregnenolone, the precursor of all steroids. In tissues or organs that are not directly involved in steroidogenesis, TSPO could be involved in a protective effect against lesion-promoting mechanisms like apoptosis and maintain mitochondrial integrity [18]. 


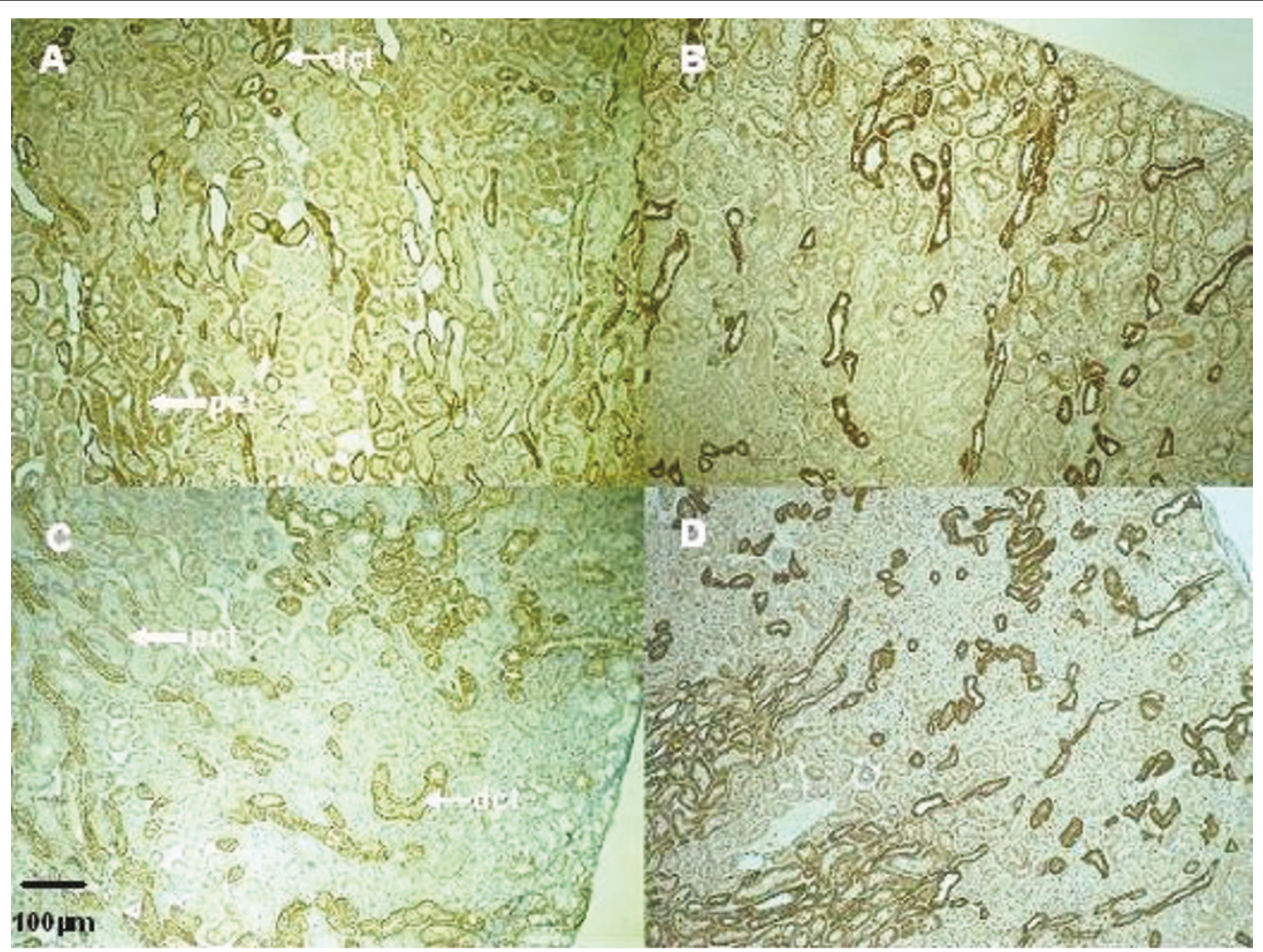

Figure 5 Representative renal TSPO staining in the outer medulla in kidneys from male (A, B) and female rats (C, D); after ischemia followed by $1(A, C)$ or 5 days of reperfusion $(B, D)$ (Magnification $\times 100$ ). At Day 1, Kidneys from male rats exhibited a faint transient cytoplasm staining in proximal tubule epithelial cells. pct: proximal convoluted tubule; dct: distal convoluted tubule.

In conclusion, we showed that male rats were more sensitive to renal IRI than female rats. These gender differences were found in tubular injury development, as well as in the nephrogenic repair process indicated by PCNA and vimentin expression. This sensitivity was associated with modulation of male sex hormone production in response to renal IRI. This adaptive response could be related to an extension of organ failure or a compensatory mechanism to limit renal injury. In addition, TSPO expression was transiently increased in proximal tubules in male rats during IRI process, supporting a putative role of this protein, which will be defined with further studies.

\section{Acknowledgements}

We thank Franck Berneron (Animalerie, CHU de Poitiers, Faculté de Médecine et de Pharmacie de Poitiers), Béatrice Fernandez, Nathalie Quellard (Laboratoire d'Anatomie et Cytologie Pathologiques, CHU de Poitiers) and Christine Millet (Pôle de Biologie, CHU de Poitiers) for their excellent technical support.

This work has been supported in part by a grant from the French society of critical care: SRLF: Société de Réanimation de Langue Française.

\section{Author details}

${ }^{1} \mathrm{CHU}$ Poitiers, Service de Réanimation Médicale Poitiers, F-86000, France.

${ }^{2} \mathrm{CHU}$ Poitiers, Service des Urgences, Poitiers, F-86000, France. ${ }^{3} \mathrm{CHU}$ Poitiers,
Service de Biochimie, Poitiers, F-86000, France. ${ }^{4} \mathrm{CHU}$ Poitiers, Service d'Anatomopathologie, Poitiers, F-86000, France. ${ }^{5}$ Inserm U927, Poitiers, F86000, France; Université de Poitiers, Faculté de Médecine et de Pharmacie, Poitiers, F-86000, France.

\section{Authors' contributions}

DAH participated in the design of the study and performed experiments. FF participated in the design of the study and performed experiments and the statistical analysis. JMG performed histopathological analysis, including immunostaining. RR and TH conceived of the study, and participated in its design and coordination. RR, TH and GM helped to draft the manuscript. All authors read and approved the final manuscript.

\section{Competing interests}

The authors declare that they have no competing interests.

Received: 5 November 2010 Accepted: 9 June 2011

Published: 9 June 2011

\section{References}

1. Spitzer JA, Zhang P: Protein tyrosine kinase activity and the influence of gender in phagocytosis and tumor necrosis factor secretion in alveolar macrophages and lung-recruited neutrophils. Shock 1996, 6:426-433.

2. Miller L, Hunt JS: Sex steroid hormones and macrophage function. Life SCi 1996, 59:1-14.

3. Angele MK, Schwacha MG, Ayala A, Chaudry IH: Effect of gender and sex hormones on immune responses following shock. Shock 2000, 14:81-90.

4. Spitzer JA, Zhang P: Gender differences in phagocytic response in the blood and liver, and the generation of cytokine induced neutrophil chemoattractant in the liver of acutely ethanol-intoxicated rats. Alcohol Clin Exp Res 1996, 20:914-920. 
5. Robert R, Spitzer JA: Effect of female hormones (17b-estradiol and progesterone) on nitric oxide production by alveolar macrophages in rats. Nitric Oxide 1997, 1:453-462.

6. Hale SL, Birnbaum Y, Kloner RA: beta-Estradiol, but not alpha-estradiol, reduced myocardial necrosis in rabbits after ischemia and reperfusion. Am Heart J 1996, 132:258-262.

7. Squadrito F, Altavilla D, Squadrito G, Campo GM, Arlotta M, Arcoraci V, Minutoli L, Serrano M, Saitta A, Caputi AP: 17Beta-oestradiol reduces cardiac leukocyte accumulation in myocardial ischaemia reperfusion injury in rat. Eur J Pharmacol 1997, 335:185-192.

8. Zhai P, Eurell TE, Cotthaus R, Jeffery EH, Bahr JM, Gross DR: Effect of estrogen on global myocardial ischemia-reperfusion injury in female rats. Am J Physiol Heart Circ Physiol 2000, 279:H2766-2775.

9. Harada H, Pavlick KP, Hines IN, Lefer DJ, Hoffman JM, Bharwani S, Wolf RE, Grisham MB: Sexual dimorphism in reduced-size liver ischemia and reperfusion injury in mice: role of endothelial cell nitric oxide synthase. Proc Natl Acad Sci 2003, 100:739-744.

10. Eckhoff DE, Bilbao G, Frenette L, Thompson JA, Contreras JL: 17-Betaestradiol protects the liver against warm ischemia/reperfusion injury and is associated with increased serum nitric oxide and decreased tumor necrosis factor-alpha. Surgery 2002, 132:302-309.

11. Muller V, Losonczy G, Heemann U, Vannay A, Fekete A, Reusz G, Tulassay T, Szabo AJ: Sexual dimorphism in renal ischemia-reperfusion injury in rats: possible role of endothelin. Kidney Int 2002, 62:1364-1371.

12. $\mathrm{Hu} \mathrm{H}$, Wong G, Batteux F, Nicco C: Gender difference in the susceptibility to renal ischemia-reperfusion injury in BALB/c mice. Tohoku J Exp Med 2009, 218:325-329.

13. Park KM, Kim Jl, Bonventre AJ, Bonventre JV: Testosterone is responsible for enhanced susceptibility of males to ischemic renal injury. J Biol Chem 2004, 279:52282-5292.

14. Godet C, Goujon JM, Petit I, Lecron JC, Hauet T, Mauco G, Carretier M Robert : Endotoxin-tolerance decreases Ischemia-Reperfusion renal injury in rats: potential role of Interleukin-10. Shock 2006, 25:384-388.

15. Jayle C, Favreau F, Zhang K, Doucet C, Goujon JM, Hebrard W, Carretier M, Eugene M, Mauco G, Tillement JP, Hauet : Comparison of protective effects of trimetazidine against experimental warm ischemia of different durations: early and long-term effects in a pig kidney model. J Physiol Renal Physiol 2007, 292:F1082-1093.

16. Papadopoulos V, Baraldi M, Guilarte TR, Knudsen TB, Lacapère JJ, Lindermann P, Norenberg MD, Nutt D, Weizman A, Zhang MR, Gavish M: Translocator protein (18kDA): new nomenclature for the peripheral-type benzodiazepine receptor based on its structure and molecular function. Trends Pharmacol Sci 2006, 27:402-409.

17. Lacapere JJ, Papadopoulos V: Peripheral-type benzodiazepine receptor: structure and function of a cholesterol-binding protein in steroid and bile acid biosynthesis. Steroids 2003, 68:569-585.

18. Favreau F, Rossard L, Zhang K, Desurmont T, Manguy E, Belliard A, Fabre S, Liu J, Han Z, Thuillier R, Papadopoulos V, Hauet T: Expression and modulation of translocator protein and its partners by hypoxia reoxygenation or ischemia and reperfusion in porcine renal models. Am J Renal Physiol 2009, 297:F177-F190.

19. Hauet T, Han Z, Wang Y, Hameury F, Jayle C, Gibelin H, Goujon JM Eugene M, Papadopoulos V: Modulation of peripheral-type benzodiazepine receptor levels in a reperfusion injury pig kidney-graft model. Transplantation 2002, 74:1507-1515.

20. Goujon JM, Hauet T, Menet E, Levillain P, Babin P, Carretier M: Histological evaluation of proximal tubule cell injury in isolated perfused pig kidneys exposed to cold ischemia. J Surg Res 1999, 82:228-233.

21. Wright $G$, Reichenbecher $V$ : The effect of superoxide and the peripheral benzodiazepine receptor ligands on the mitochondrial processing of manganese-dependent superoxide dismutase. Exp Cell Res 1999, 246:443-450

22. Fekete A, Vannay A, Ver A, Vasarhelyi B, Muller V, Ouyang N, Reusz G, Tulassay T, Szabo AJ: Sex difference in the alteration of $\mathrm{Na}+, \mathrm{K}+-$ ATPase following ischemia-reperfusion injury in the rat kidney. J Physiol 2003, 555(2):471-480.

23. Takayama J, Takaoka M, Sugino Y, Yamamoto Y, Ohkita M, Matsumura $Y$ Sex Difference in Ischemic Acute Renal Failure in Rats: Approach by Proteomic Analysis. Biol Pharm Bull 2007, 30:1905-1912.

24. Choudhry MA, Bland $\mathrm{Kl}$, Chaudry $\mathrm{H}$ : Insight into the mechanism of gender-specific response to trauma-hemorrhage. In Yearbook of intensive care and emergency medicine. Edited by: Vincent $\lrcorner$ Berlin, Heidelberg. NewYork: Springer -Verlag; 2007:869-879.

25. Christeff N, Auclair MC, Thobie N, Fertil B, Carli A, Nunez EA: Effect of estradiol on endotoxin-induced changes in steroid hormone levels and lethality in male rats. Circ Shock 1994, 44:154-159.

26. Choudhry MA, Bland $\mathrm{Kl}$, Chaudry $\mathrm{IH}$ : Trauma and immune response-effect of gender differences. Injury 2007, 38:1382-1391.

27. Schneider CP, Nickel EA, Samy TS, Schwacha MG, Cioffi WG, Bland KI, Chaudry $\mathrm{H}$ : The aromatase inhibitor, 4-hydroxyandrostenedione, restores immune responses following trauma-hemorrhage in males and decreases mortality from subsequent sepsis. Shock 2000, 14:347-353.

28. Witzgall R, Brown D, Schwartz C, Bonventre JV: Localization of proliferating cell nuclear antigen, vimentin, c-Fos, and clusterin in the postischemic kidney. Evidence for a heterogenous genetic response among nephron segments, and a large pool of mitotically active and dedifferentiated cell. J Clin Invest 1994, 93:2175-2188.

29. Bonventre $\mathrm{JV}$, Weinberg JM: Recent advances in the pathophysiology of ischemic acute renal failure. J Am Soc Nephrol 2003, 8:2199-2210.

30. Vongwiwatana A, Tasanarong A, Rayner DC, Melk A, Halloran PF: Epithelial to mesenchymal transition during late deterioration of human kidney transplants: the role of tubular cells in fibrogenesis. Am J Transplant 2005, 5:1367-1374

31. Jassem W, Fuggle SV, Rela M, Koo DD, Heaton ND: The role of mitochondria in ischemia/reperfusion injury. Transplantation 2002, 73:493-499.

32. Benitez-Bribiesca L, Gomez-Camarillo M, Castellanos-Juarez E, Mravko E, Sanchez-Suarez P: Morphologic, biochemical and molecular mitochondrial changes during reperfusion phase following brief renal ischemia. Ann N Y Acad Sci 2000, 926:165-179.

33. Zhang K, Desurmont T, Goujon JM, Favreau F, Cau J, Deretz S, Mauco G, Carretier M, Papadopoulos V, Hauet T: Modulation of peripheral-type benzodiazepine receptor during ischemia reperfusion injury in a pig kidney model: a new partner of leukaemia inhibitory factor in tubular regeneration. J Am Coll Surg 2006, 203:353-364.

34. Corsi L, Geminiani E, Baraldi M: Peripheral benzodiazepine receptors in hepatic encephalopathy. Curr Clin Pharmacol 2008, 3:38-45.

35. Gobe GC, Johnson DW: Distal tubular epithelial cells of the kidney: Potential support for proximal tubular cell survival after renal injury. Int $J$ Biochem cell Biol 2007, 39:1551-1561.

36. Neuhofer W, Beck FX: Cell survival in the hostile environment of the renal medulla. Annu Rev Physiol 2005, 67:531-555.

doi:10.1186/1476-9255-8-14

Cite this article as: Robert et al:: Gender difference and sex hormone production in rodent renal ischemia reperfusion injury and repair. Journal of Inflammation 2011 8:14.

\section{Submit your next manuscript to BioMed Central and take full advantage of:}

- Convenient online submission

- Thorough peer review

- No space constraints or color figure charges

- Immediate publication on acceptance

- Inclusion in PubMed, CAS, Scopus and Google Scholar

- Research which is freely available for redistribution 